\title{
Production of Poly(3-Hydroxybutyrate) by Haloarcula, Halorubrum, and Natrinema Haloarchaeal Genera Using Starch as a Carbon Source
}

\author{
Fatma Karray $\mathbb{D D}^{1}{ }^{1}$ Manel Ben Abdallah $\mathbb{D D}^{1}{ }^{1}$ Nidhal Baccar, ${ }^{1}$ Hatem Zaghden (D), \\ and Sami Sayadi $\mathbb{1}^{2}$ \\ ${ }^{1}$ Laboratory of Environmental Bioprocesses, Centre of Biotechnology of Sfax, BP 1177, 3018 Sfax, Tunisia \\ ${ }^{2}$ Center for Sustainable Development, College of Arts and Sciences, Qatar University, Doha 2713, Qatar \\ Correspondence should be addressed to Fatma Karray; karray.fatma@gmail.com and Sami Sayadi; sami.sayadi@gmail.com
}

Received 26 June 2020; Revised 15 January 2021; Accepted 19 January 2021; Published 27 January 2021

Academic Editor: Stefan Spring

Copyright (C) 2021 Fatma Karray et al. This is an open access article distributed under the Creative Commons Attribution License, which permits unrestricted use, distribution, and reproduction in any medium, provided the original work is properly cited.

\begin{abstract}
Microbial production of bioplastics, derived from poly(3-hydroxybutyrate) (PHB), have provided a promising alternative towards plastic pollution. Compared to other extremophiles, halophilic archaea are considered as cell factories for PHB production by using renewable, inexpensive carbon sources, thus decreasing the fermentation cost. This study is aimed at screening 33 halophilic archaea isolated from three enrichment cultures from Tunisian hypersaline lake, Chott El Jerid, using starch as the sole carbon source by Nile Red/Sudan Black staining and further confirmed by PCR amplification of phaC and phaE polymerase genes. 14 isolates have been recognized as positive candidates for PHA production and detected during both seasons. The identification of these strains through $16 \mathrm{~S}$ rRNA gene analyses showed their affiliation to Halorubrum, Natrinema, and Haloarcula genera. Among them, three PHB-producing strains, CEJ34-14, CEJ5-14, and CEJ48-10, related to Halorubrum chaoviator, Natrinema pallidum, and Haloarcula tradensis were found to be the best ones reaching values of $9.25,7.11$, and $1.42 \%$ of cell dry weight (CDW), respectively. Our findings highlighted that Halorubrum, Natrinema, and Haloarcula genera were promising candidates for PHB production using soluble starch as a carbon source under high salinity $\left(250 \mathrm{~g} \mathrm{~L}^{-1} \mathrm{NaCl}\right)$.
\end{abstract}

\section{Introduction}

Plastic is a highly useful material, and its production is growing. Million tons of nondegradable plastics end up in our natural environment every year affecting our health, wildlife, terrestrial, and marine habitats [1]. For this reason, polyhydroxyalkanoates (PHAs) are biodegradable and biocompatible polymers which have been promoted as an alternative to conventional oil-based plastics [2, 3]. PHAs are synthesized by a wide variety of bacteria and archaea from various carbon sources and served as intracellular storage compounds to survive under unbalanced conditions $[4,5]$. Extremely halophilic archaea, inhabiting hypersaline environments containing high salt concentrations, are preferred for various potential applications, including the synthesis of polyhydroxyalkanoates. Poly(3-hydroxybutyrate) (PHB) was the first bioplastic found in species of Dead Sea Halobacterium described in 1972 [6]. Since then, microorganisms including extremely halophilic archaea belonging to the genera Haloquadratum, Halorubrum, Halobacterium, Haloterrigena, Haloferax, Natronococcus, Natronobacterium, Haloarcula, Natrinema, Halogeometricum, Halopiger, Halobiforma, and Halococcus have also been found to accumulate considerable amounts of PHB [7-9] using colony/cell staining methods, molecular tools targeting PHA synthase genes, and analytical techniques such as Fourier transform infrared spectroscopy, crotonic acid assays, gas chromatography, and liquid chromatography [10].

These organisms could utilize various renewable carbon sources and release the PHB easily by cell lysis in distilled water, thus lowering its high production cost [11]. Several recent investigations have shown that the productivities of 
PHB by archaeal strains were obtained using glucose as the sole carbon source $[9,12,13]$ than with other substrates (wastes and pretreated vinasse) $[14,15]$. However, few studies based on the exploration of PHB production by archaeal species using starch have been reported, despite its wide availability [16, 17]. Therefore, it was important to select strains able to use starchy substrates for PHB biosynthesis.

Chott El Jerid, the largest Salt Lake, is located in the south of Tunisia. Furthermore, this lake is the biggest one in the north of Africa $\left(5360 \mathrm{~km}^{2}\right)$ with a salt concentration above $33 \% \mathrm{NaCl}$ [18]. It has a thalassohaline salt composition, despite its continental origin. It may be flooded in the winter and evaporates to a desert in the dry season. These climatic conditions make the Chott an ephemeral extreme environment. Our previous studies described microbial diversity in Chott El Jerid during wet and dry seasons, using culture and molecular methods. Halophilic anaerobic fermentative bacterial strains were isolated from surface sediments [19, 20]. Culture-independent techniques, targeting 16S rRNA and functional markers encoding the dissimilatory sulfite reductase beta-subunit gene $(d s r B)$, methyl coenzyme $\mathrm{M}$ reductase $(m c r A)$, showed abundant and diverse prokaryotic communities, sulfate-reducing bacteria (SRB), and methanogens, respectively $[20,21]$. Additionally, the isolation of halophilic aerobic bacterial and archaeal strains producing extracellular hydrolases have been achieved in Chott El Jerid [22]. Because Archaea outnumbered Bacteria in the studied samples, our purpose, here, is to expand the possibility of PHA synthesis by Archaea from Chott El Jerid. The objectives of this research were (1) enrichment, isolation, and screening PHA-accumulating halophilic archaea in water or water/sediment mix samples collected from Chott El Jerid in both seasons using phenotypic and molecular methods; (2) identification and characterization of PHA-producing isolates, utilizing starch as the carbon source; and (3) identification and quantification of the polymer produced.

\section{Materials and Methods}

2.1. Sample Collection. The samples (S1-10) and (S6M-14; S6W-14) were collected in dry (October 2010) and wet seasons (January 2014) from a continental ephemeral lake, Chott El Jerid, respectively. Hypersaline water or water/sediment mix samples were collected at different locations, approximately $0-10 \mathrm{~cm}$ from the surface. The samples were collected in sterile bottles, brought to the laboratory within three hours, and kept aseptically at $4^{\circ} \mathrm{C}$ until analyses. The environmental parameters of sampling sites are listed in Table 1 as previously reported [20].

2.2. Enrichment and Isolation of Polyhydroxyalkanoic Acids (PHA) Producing Archaea. Samples were enriched by culturing in PHA-accumulating medium (per liter $\mathrm{NaCl}, 250 \mathrm{~g}$; $\mathrm{MgCl}_{2} .6 \mathrm{H}_{2} \mathrm{O}, 10 \mathrm{~g} ; \mathrm{MgSO}_{4} .7 \mathrm{H}_{2} \mathrm{O}, 15 \mathrm{~g} ; \mathrm{KCl}, 4 \mathrm{~g} ; \mathrm{CaCl}_{2}, 2$ $\mathrm{H}_{2} \mathrm{O}, 1 \mathrm{~g} ; \mathrm{NaHCO}_{3}, 0.5 \mathrm{~g}$; yeast extract, $1 \mathrm{~g}$ ) supplemented with $1 \%$ soluble starch at $37^{\circ} \mathrm{C}$ for 7 days at $180 \mathrm{rpm}$.

In order to isolate PHA-producing haloarchaea, samples were serially diluted and $100 \mu \mathrm{L}$ of each dilution were plated onto agar medium $\left(20 \mathrm{gL}^{-1}\right)$ as described above. Following incubation, 33 colonies from the plates were picked as a result of their pigmentation and/or morphology and were transferred onto fresh plates several times until pure culture was obtained. Colonies were differentiated by colour, shape, and edge appearance. Morphological features of cells were examined using oil immersion at 100x objective (Optika, B-500 ERGO Model, Italy).

2.3. Extraction of Genomic DNA. When the growth of archaeal cultures reached the exponential phase, the extraction of genomic DNA was performed using the GF-1 Nucleic Acid Extraction Kit (Vivantis Technologies Sdn Bhd, Selangor DE, Malaysia) according to the manufacturer's instructions.

2.4. Identification of Archaeal Strains. PCR amplification was achieved using the primer set $21 \mathrm{~F}\left(5^{\prime}\right.$-TTCCGGTTGATCC YGCCGGA-3 ${ }^{\prime}$ ) [23] and 1492R ( $5^{\prime}$-GGTTACCTTGTTAC GACTT- $3^{\prime}$ ) [24]. The PCR reaction was realized in a $50 \mu \mathrm{L}$ mixture containing $1.25 \mathrm{U}$ of Taq polymerase (Fermentas), 1x PCR buffer, $200 \mu \mathrm{M}$ of dNTP, $0.2 \mu \mathrm{M}$ of each primer, and $50 \mathrm{ng}$ of genomic DNA. Thirty cycles $\left(1 \mathrm{~min} 94^{\circ} \mathrm{C}\right.$; $1 \min 55^{\circ} \mathrm{C} ; 2 \min 72^{\circ} \mathrm{C}$ ) were carried out using a thermocycler (Applied Biosystems, USA). The amplified PCR products of size 1500 bp were analyzed by electrophoresis in 1\% agarose gels and photographed with a Gel Doc XR Imaging system (Bio-Rad). Then, the restriction analysis was performed by digesting $10 \mu \mathrm{L}$ of PCR products with $10 \mathrm{U}$ of restriction enzymes AluI and $M b o \mathrm{I}$ while HaeIII $\left(8 \mathrm{U}_{\mu} \mathrm{L}^{-1}\right)$ and the appropriate restriction buffer in a final volume of $20 \mu \mathrm{L}$ for 3 hours at $37^{\circ} \mathrm{C}$. These enzymes (Life Technologies), frequently used in restriction analysis, gave the most significant differences between species. 16S rRNA fragments, acquired after enzymatic digestion, were separated on 3\% agarose gels for $4 \mathrm{~h}$ at $50 \mathrm{~V}$ and photographed with a Gel Doc system. The original PCR products of positive isolates selected by comparing enzymatic restriction patterns and described as PHA-producing isolates in the following section were purified with PureLink ${ }^{\circledR}$ Quick Gel Extraction and PCR Purification Combo Kit (Cat. No. K220001, Invitrogen, Carlsbad, USA) following the manufacturer's instructions prior to cloning. The purified PCR products were ligated into pGEM-T easy (Promega Corporation, Madison, WI) system as recommended by the manufacturer. The ligation mixture was transformed into $\mathrm{DH} 5 \alpha$ competent cells. Recombinant plasmids were verified by EcoRI digestion and chosen for sequencing. Sequencing and phylogenetic analysis were performed as previously reported [25].

2.5. Screening of Potential Halophilic PHA Producers. All isolates were subjected to PHA screening by Sudan Black B (SBB) and confirmed by Nile Red (NR) staining (Sigma), a more specific stain. Staining of colonies was done using $0.3 \%$ alcoholic solution of Sudan Black B. PHA-producing colonies appeared black [26]. Nile Red stain (25\% (w/v) stock solution in dimethylsulfoxide (DMSO)) was directly inoculated in duplicate $\left(0.5 \mu \mathrm{g} \mathrm{mL} \mathrm{m}^{-1}(\mathrm{w} / \mathrm{v})\right)$ in agar medium containing $1 \%(\mathrm{w} / \mathrm{v})$ starch and growth cells occurred in the presence of the dye. The strain Escherichia coli was used as 
TABLE 1: Sampling locations, conditions, and distribution of halophilic isolates.

\begin{tabular}{lccccccc}
\hline Sample type & Sample & Site & Geographical location & pH & Salinity $(\%)$ & Temperature $\left({ }^{\circ} \mathrm{C}\right)$ & Total number of isolates \\
\hline Water and sediments & S1-10 & Site 1 & $33^{\circ} 54^{\prime} 42.21^{\prime \prime} \mathrm{N} 8^{\circ} 31^{\prime} 7.98^{\prime \prime} \mathrm{E}$ & 6.61 & 34.6 & 23 & 11 \\
Water and sediments & S6M-14 & Site 2 & $33^{\circ} 54^{\prime} 44.15^{\prime \prime} \mathrm{N} 8^{\circ} 31^{\prime} 9.01^{\prime \prime} \mathrm{E}$ & 7.61 & 27.6 & 19 & 20 \\
Hypersaline water & S6W-14 & Site 2 & $33^{\circ} 54^{\prime} 44.15^{\prime \prime} \mathrm{N} 8^{\circ} 31^{\prime} 9.01^{\prime \prime} \mathrm{E}$ & 7.61 & 27.6 & 19 & 2 \\
\hline
\end{tabular}

a negative control. Natrinema altunense strain CEJGTEA101 [KY129977] was identified as a PHA-producing isolate in our previous work [9] and was used as a positive control in this study. After 15 days of incubation at $37^{\circ} \mathrm{C}$, the isolates which revealed orange fluorescence after exposure of plates to UV light were selected as PHA accumulators [27]. Staining of promising cells with Nile Red was done using a fluorescence microscope (Olympus BX51) [28].

In parallel, all isolates were screened for their genetic potential for polyhydroxyalkanoate production. The genes responsible for PHA production in haloarchaea were clustered in the class III synthases which were constituted of two subunits (PhaE and PhaC). PCR technique was used for screening archaeal polyhydroxyalkanoate producers using two pairs of codehops (codehopEF/codehopER) and (codehopCF/codehopCR), according to the highly conserved regions in $P h a E$ and $P h a C$, respectively $[29,30]$. The primers codehopEF (5'-CGACCGAGTTCCGCGAYATHTGGYT$\left.3^{\prime}\right)$ and codehopER (5'-GCGTGCTGGCGGCKYTCNAVYTC- $3^{\prime}$ ) were used to amplify the PhaE polymerase gene. The amplification of the PhaC polymerase gene was performed using the primers codehopCF $\left(5^{\prime}\right.$-ACCGACGTC GTCTACAAGGARAAYAARYT- $\left.3^{\prime}\right)$ and codehopCR (5' -GGTCGCGGACGACGTCNACRCARTT-3') [30]. The PCR condition was as follows: after initial denaturation $\left(94^{\circ} \mathrm{C}\right.$ for $\left.5 \mathrm{~min}\right), 30$ cycles of $94^{\circ} \mathrm{C}$ for $30 \mathrm{~s}, 55^{\circ} \mathrm{C}$ for $45 \mathrm{~s}$, and $72^{\circ} \mathrm{C}$ for $45 \mathrm{~s}$ were performed, followed by a final extension $\left(10 \mathrm{~min}, 72^{\circ} \mathrm{C}\right)$. PCR amplification was run on a thermocycler (Applied Biosystems) using 1.25 $\mathrm{U}$ of Taq DNA polymerase (Fermentas), 1x PCR buffer, $0.2 \mu \mathrm{M}$ of each primer, $200 \mu \mathrm{M}$ of DNTP, and $50 \mathrm{ng}$ DNA template. The PCR products were subjected to electrophoresis using $2 \%$ agarose gels.

2.6. Growth Kinetics of Potential PHA Producers. The strains were cultivated in $50 \mathrm{~mL}$ of PHA-producing medium amended with $10 \mathrm{gL}^{-1}$ starch. The cultures in Erlenmeyer flasks were incubated in duplicate at $37^{\circ} \mathrm{C}, 180 \mathrm{rpm}$. Absorbance at $600 \mathrm{~nm}$ was determined using a UV-visible spectrophotometer (Shimadzu UV-1800, Japan) each $24 \mathrm{~h}$ for each PHA-producing strain.

2.7. Determination of Cell Dry Weight (CDW). Cultures grown to late logarithmic phase were centrifuged at $6000 \mathrm{rpm}$ for $30 \mathrm{~min}$; then, cells were washed twice with distilled water. The supernatant was discarded leaving the pellet, which was lyophilized and weighed.

2.8. Determination of PHB Content in Potential Halophilic PHA Producers by Gas Chromatography (GC). After methanolysis, the cellular content of the polymer and its compo- sition were assayed by gas chromatography (GC) using an Agilent Technologies 7890A chromatograph, equipped with a capillary column $(30 \mathrm{~m} \times 0.25 \mathrm{~mm} \times 0.25 \mu \mathrm{m})$ and a flame ionization detector (FID) as previously reported [31]. Samples were analyzed in duplicate. The standard PHB (Sigma-Aldrich, USA) was used for calibration. The PHB content in the cells was determined as (mass of $\mathrm{PHB} / \mathrm{cell}$ dry mass) $\times 100 \%$. The peak at $4.4 \mathrm{~min}$ represents the 3 hydroxybutyrate methylester.

\section{Results}

3.1. Screening of PHA-Producing Isolates by Staining Procedures. A large number of orange, red, and pink colonies were picked and purified by repeating subculturing. A total of 33 extremely halophilic strains were isolated from three tested enrichment cultures and were screened for PHA accumulation (Table 2). 11, 20, and 2 isolates were obtained from the water/sediment mix of the sample S1-10, water/sediment mix of the sample S6M-14, and hypersaline water of the sample S6W-14, respectively. 14 positive isolates were selected after staining by Sudan Black B (Figure S1 (a)). Additionally, they showed high fluorescence intensity with Nile Red when exposed to ultraviolet (Figure S1 (b)). The positive control strain exhibited orange fluorescence under UV light.

3.2. Screening of PHA Synthase Genes by Degenerate Polymerase Chain Reaction. As a result, the screening of 33 strains showed the detection of 14 strains as PHA producers. The same strains, which showed positive results with phenotypic methods (Sudan Black and Nile Red), gave bands of approximately $230 \mathrm{bp}$ (phaE) and $280 \mathrm{bp}$ (phaC) (Table 2; Figure S2).

3.3. Morphological Characterization of Potential PHA Producers. The cells of all isolates were rods, cocci, and pleomorph (Table 2). All selected strains as producers were round. The approximate cell dimensions were 1 to $2 \mu \mathrm{m}$ (Figure S3).

3.4. Phylogenetic Analysis. 33 haloarchaeal isolates were examined with ARDRA analysis. The comparison of three enzymes HaeIII, AluI, and MboI digestion patterns withisolates showed the occurrence of six different patterns for archaea (Table 2). Three profiles grouped polyhydroxyalkanoate-producing strains. The strains CEJ314, CEJ5-14, CEJ6-14, CEJ7-14, CEJ8-14, CEJ9-14, CEJ1014, CEJ11-14, CEJ21-14, CEJ24-14, CEJ25-14, and CEJ2814 were clustered into profile III. The strain CEJ34-14 was grouped into profile I. ARDRA pattern $\mathrm{V}$ represented the isolate CEJ48-10 (Figure S4). The phylogenetic analysis 
TABLE 2: Screening of PHA-producing archaeal strains using phenotypic and genotypic methods.

\begin{tabular}{|c|c|c|c|c|c|c|c|}
\hline \multirow[t]{2}{*}{ Sample type } & \multirow[t]{2}{*}{ Name of isolates } & \multirow[t]{2}{*}{ Morphology } & \multicolumn{2}{|c|}{$\begin{array}{l}\text { Colony } \\
\text { staining } \\
\text { method }\end{array}$} & \multicolumn{2}{|c|}{ CODEHOP PCR } & \multirow{2}{*}{$\begin{array}{l}\text { ARDRA } \\
\text { Profiles }\end{array}$} \\
\hline & & & SBB & NR & PhaE & PhaC & \\
\hline \multirow{20}{*}{ Water and sediments (2014) } & CEJ1-14 & Cocci & - & - & - & - & I \\
\hline & CEJ2-14 & Cocci & - & - & - & - & II \\
\hline & CEJ3-14 & Cocci & + & + & + & + & III \\
\hline & CEJ4-14 & Cocci & - & - & - & - & I \\
\hline & CEJ5-14 & Cocci & + & + & + & + & III \\
\hline & CEJ6-14 & Cocci & + & + & + & + & III \\
\hline & CEJ7-14 & Cocci & + & + & + & + & III \\
\hline & CEJ8-14 & Cocci & + & + & + & + & III \\
\hline & CEJ9-14 & Cocci & + & + & + & + & III \\
\hline & CEJ10-14 & Cocci & + & + & + & + & III \\
\hline & CEJ11-14 & Cocci & + & + & + & + & III \\
\hline & CEJ17-14 & Pleomorph & - & - & - & - & I \\
\hline & CEJ18-14 & Pleomorph & - & - & - & - & I \\
\hline & CEJ21-14 & Cocci & + & + & + & + & III \\
\hline & CEJ24-14 & Cocci & + & + & + & + & III \\
\hline & CEJ25-14 & Cocci & + & + & + & + & III \\
\hline & CEJ26-14 & Cocci & - & - & - & - & I \\
\hline & CEJ28-14 & Cocci & + & + & + & + & III \\
\hline & CEJ29-14 & Short rod & - & - & - & - & I \\
\hline & CEJ32-14 & Cocci & - & - & - & - & II \\
\hline \multirow{2}{*}{ Water (2014) } & CEJ33-14 & Cocci & - & - & - & - & I \\
\hline & CEJ34-14 & Cocci & + & + & + & + & $\mathrm{I}$ \\
\hline \multirow{11}{*}{ Water and sediments (2010) } & CEJ35-10 & Cocci & - & - & - & - & IV \\
\hline & CEJ36-10 & Cocci & - & - & - & - & IV \\
\hline & CEJ37-10 & Cocci & - & - & - & - & IV \\
\hline & CEJ38-10 & Cocci & - & - & - & - & IV \\
\hline & CEJ41-10 & Cocci & - & - & - & - & VI \\
\hline & CEJ42-10 & Cocci & - & - & - & - & VI \\
\hline & CEJ43-10 & Cocci & - & - & - & - & IV \\
\hline & CEJ45-10 & Cocci & - & - & - & - & IV \\
\hline & CEJ46-10 & Cocci & - & - & - & - & IV \\
\hline & CEJ47-10 & Cocci & - & - & - & - & I \\
\hline & CEJ48-10 & Cocci & + & + & + & + & $\mathrm{V}$ \\
\hline
\end{tabular}

Designation of isolates by letters indicating first the origin of strains from Chott El Jerid (CEJ) followed by the number of the isolates, then a number indicating the year of sampling. The ARDRA pattern is indicated by Roman numeral. +, detectable; -, not detectable; SBB: Sudan Black B; NR: Nile Red.

targeting the $16 \mathrm{~S}$ rRNA genes of isolates indicated that the genera were Natrinema, Haloarcula, and Halorubrum. The isolate CEJ34-14 was related to Halorubrum chaoviator DSM 19316. The isolates CEJ3-14, CEJ5-14, CEJ6-14, CEJ7-14, CEJ8-14, CEJ9-14, CEJ10-14, CEJ11-14, CEJ21-14, CEJ24-14, CEJ25-14, and CEJ28-14 showed close relatedness to species of the most abundant genus Natrinema. Finally, the strain CEJ48-10 belonged to the genus Haloarcula (Figure 1).

3.5. Quantitative Estimation of PHB Production by Positive Haloarchaeal Isolates. The data in Table 3 showed that the
PHB content in the cells was ranged from $0.07 \%$ up to 9.25\% of CDW. Among the strains studied, the isolates CEJ34-14, CEJ5-14, and CEJ48-10 affiliated with Halorubrum chaoviator (99.7\% of similarity), Natrinema pallidum (99.33\% of similarity), and Haloarcula tradensis (97.72\% of similarity) were found to be the best ones, respectively. Their cells were observed under a fluorescence microscope (Figure 2). The isolate CEJ34-14 should be highlighted because it exhibited a higher $\mathrm{PHB}$ production and a higher growth rate after $48 \mathrm{~h}$ of culture. Its growth increased with a logarithmic phase of 2 days and attained a long stationary phase. However, the growth of strains CEJ5-14 and CEJ48- 


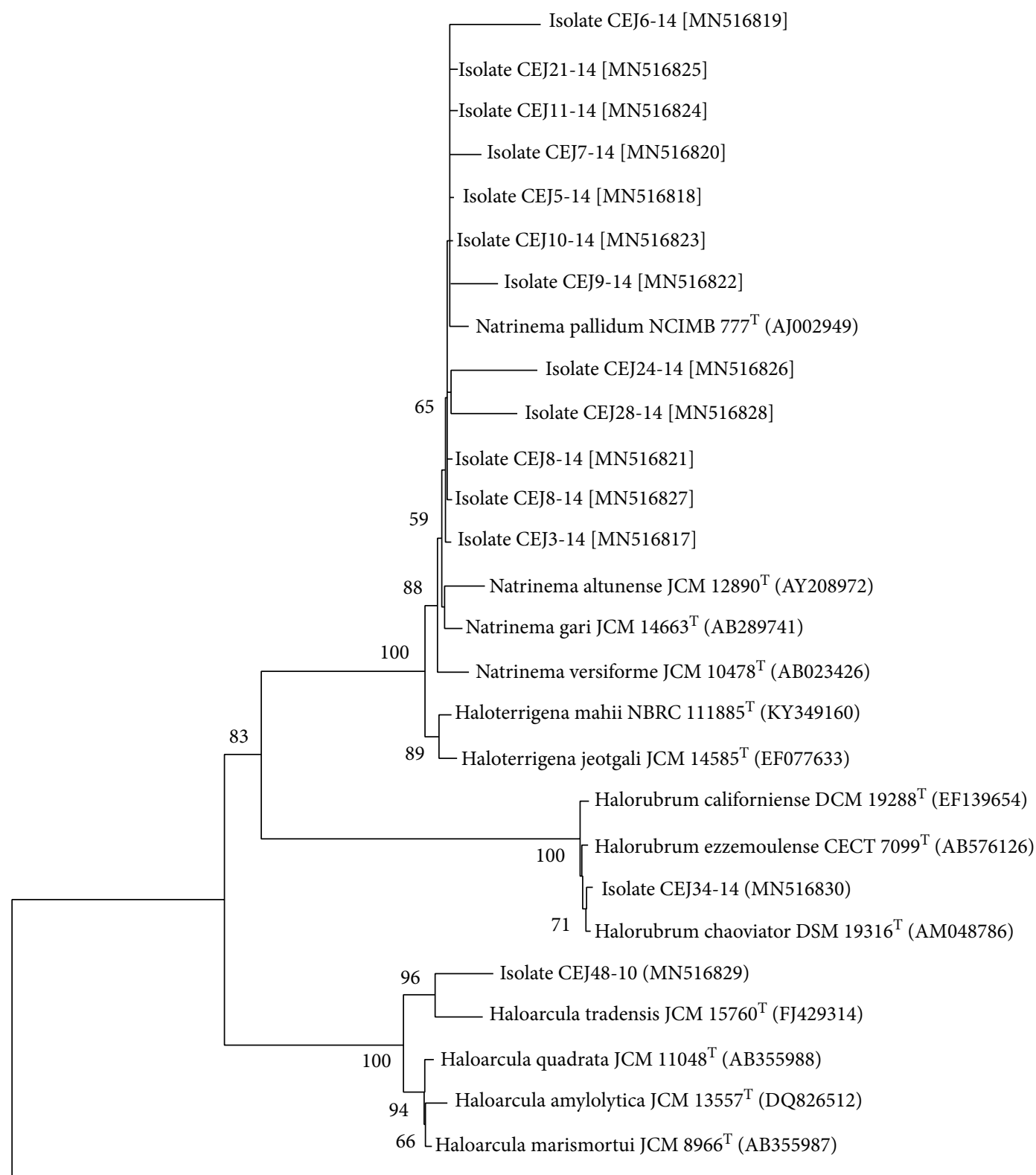

Methanohalobium evestigatum DSM3721 ${ }^{\mathrm{T}}$ (FR733675)

0.020

FIgURE 1: Phylogenetic tree, reconstructed by the neighbor-joining method, showing the positions of PHA-accumulating haloarchaeal isolates. Bootstrap values based on 1000 replicates are indicated. The sequence of Methanohalobium evestigatum was used as the outgroup.

10 requested 3 or 4 days to reach the logarithmic phase (Figure 3). Remarkably, the strains CEJ8-14, CEJ9-14, and CEJ28-14 exhibited a higher biomass production (1150$3620 \mathrm{mg} \mathrm{L}^{-1}$ ) but a lower PHB production (Table 3). Comparing to the standard $\mathrm{PHB}$, the GC spectrum of $\mathrm{PHA}$ obtained by the isolates CEJ34-14, CEJ5-14, and CEJ48-10 showed predominant peaks at retention time at $4.17,4.11$, and 4.43 minutes corresponding to poly(3-hydroxybutyrate), respectively (Figure 4). These strains exhibited PHB content of about $9.25,7.11$, and $1.42 \%$ of the cell dry weight, respectively. The growth curves and chromatograms of the other strains were presented in supplementary materials (Figures S5 and S6).

\section{Discussion}

The development of biodegradable plastics represents an alternative way to respond to problems associated with plastic waste. Polyhydroxyalkanoates are considered to be excellent candidates for biodegradable plastics. Extremely halophilic archaea have the ability to synthesize and accumulate PHA as inclusions in their cells $[11,32]$. In this study, an 
TABLE 3: PHB production values by isolates and its closest relatives.

\begin{tabular}{|c|c|c|c|c|c|c|}
\hline Strain $^{\mathrm{a}}$ & Carbon source & $\operatorname{Time}^{\mathrm{b}}(\mathrm{h})$ & $\mathrm{CDW}\left(\mathrm{mg} \mathrm{L}^{-1}\right)$ & PHA content ${ }^{\mathrm{c}}(\%)$ & Type of PHA & References \\
\hline CEJ3-14 & \multirow{14}{*}{ Starch } & 120 & 380 & 0.38 & \multirow{14}{*}{ PHB } & \multirow{14}{*}{ This study } \\
\hline CEJ5-14 & & 168 & 560 & 7.11 & & \\
\hline CEJ6-14 & & 96 & 110 & 0.09 & & \\
\hline CEJ7-14 & & 96 & 560 & 0.69 & & \\
\hline CEJ8-14 & & 96 & 1150 & 0.07 & & \\
\hline CEJ9-14 & & 144 & 2500 & 0.1 & & \\
\hline CEJ10-14 & & 72 & 130 & 0.07 & & \\
\hline CEJ11-14 & & 96 & 480 & 0.91 & & \\
\hline CEJ21-14 & & 96 & 100 & 0.79 & & \\
\hline CEJ24-14 & & 96 & 300 & 0.89 & & \\
\hline CEJ25-14 & & 120 & 640 & 0.71 & & \\
\hline CEJ28-14 & & 96 & 3620 & 0.21 & & \\
\hline CEJ34-14 & & 144 & 220 & 9.25 & & \\
\hline CEJ48-10 & & 120 & 550 & 1.42 & & \\
\hline Haloarcula marismortui ATCC 43049 & \multirow{3}{*}{ Glucose } & 192 & n.d. & 21 & PHB & {$[12]$} \\
\hline Haloarcula amylolytica 26-3 & & \multirow{2}{*}{96} & 2500 & 4.4 & PHBV & \multirow{2}{*}[30]{} \\
\hline Haloarcula argentinensis CGMCC 1.7094 & & & 3300 & 6.5 & PHBV & \\
\hline Halorubrum litoreum 12-2 & \multirow{7}{*}{ Glucose } & \multirow{2}{*}{96} & 2500 & 2.1 & PHB & \multirow{2}{*}[30]{} \\
\hline Halorubrum trapanicum CGMCC 1.2201 & & & 1900 & 12.7 & PHBV & \\
\hline Natrinema altunense CGMCC 1.3731 & & \multirow{4}{*}{96} & 5800 & 9.1 & PHBV & \multirow{4}{*}[30]{} \\
\hline Natrinema pallidum JCM 8980 & & & 3500 & 22.9 & PHBV & \\
\hline Natrinema pellirubrum JCM 10476 & & & 2200 & 11.5 & PHB & \\
\hline $\begin{array}{l}\text { Natrinema sp. } \\
\text { XA3-1 }\end{array}$ & & & 1600 & 5.4 & PHBV & \\
\hline Natrinema ajinwuensis RMG10 & & 72 & n.d. & 61 & PHBV & {$[37]$} \\
\hline Natrinema pallidum 1KYS1 & Starch & n.d. & 75 & 53.14 & PHBV & {$[36]$} \\
\hline Natrinema altunense CEJGTEA101 & Starch & 120 & 80 & 2.7 & PHA & {$[9]$} \\
\hline
\end{tabular}

CDW: cell dry weight; PHA: polyhydroxyalkanoate; PHB: poly(3-hydroxybutyrate); PHBV: poly(3-hydroxybutyrate-co-hydroxyvalerate); n.d.: not determined. ${ }^{a}$ Incubated at $37^{\circ} \mathrm{C}$ in PHA accumulation medium supplemented with starch or glucose. ${ }^{b}$ Cells were harvested at the early stationary phase for each strain. ${ }^{c}$ PHA content in dried cells was determined using gas chromatography.

effort has been taken to search the PHB-producing archaea isolated from the hypersaline lake, Chott El Jerid, using a starchy substrate. A total of 33 isolates were obtained from three enrichment cultures. PHB was detected in 14 strains grouped in three haloarchaeal genera Haloarcula, Halorubrum, and Natrinema and clustered within the phylum Euryarchaeota including Haloarculaceae, Halorubraceae, and Natrialbaceae families, respectively. They were screened via staining means (Sudan Black B and Nile Red) which were widely used for halophilic bacteria but also successfully used for Halococci, Haloarcula, Haloferax, Halorubrum, Natronococcus, Halogeometricum, Halobacterium genera, and other haloarchaeal strains $[8,13]$. In parallel, it was evident that the detection of phaC and phaE genes were shown in the 14 archaeal cells as described above with staining methods, confirming the PHB biosynthesis. To our knowledge, few studies based on molecular characterization of the genes involved in PHB synthesis in the domain of Archaea have been investigated [33]. Importantly, one group of extremely halophilic archaea with great biotechnological importance was Haloar- cula which was genetically well understood. Han et al. [12] identified two adjacent genes $p h a E_{\mathrm{Hm}}$ and $p h a C_{\mathrm{Hm}}$ encoding two subunits of PHA synthase (class III) and showed that these genes are required for PHB synthesis in Haloarcula marismortui (cultivated on $2 \%$ glucose, production of $21 \%$ PHB of CDW) [12]. Later, Han et al. [30] confirmed the detection of phaEC genes in 18 PHB or poly(3-hydroxybutyrate-co-hydroxyvalerate) PHBV producers, including Haloarcula, Halorubrum, Natrinema, and other genera by utilizing carbohydrates either glucose or fructose [30]. More recently, it was reported that these two genes were detected in the genome of Natrinema altunense CEJGTEA101, isolated from Chott El Jerid [9].

The present study is a continuity of our previous work [9], proposing the possibility to enlarge our knowledge about PHB secretion by a large number of haloarchaeal strains from Chott El Jerid due to their several advantages: firstly, their growth at high salinity minimized microbial contamination. Secondly, the high osmotic pressure in their cells facilitated the PHB recovery. Finally, their ability to consume 


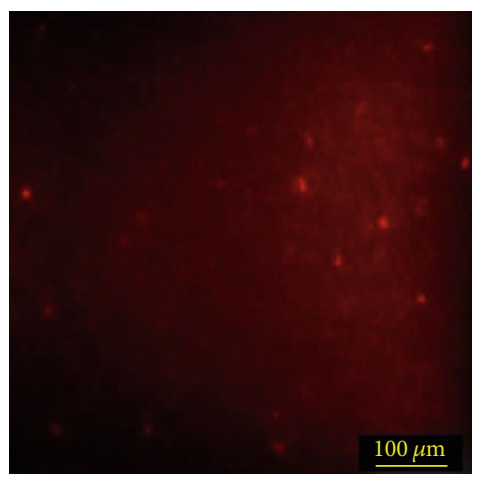

(a)

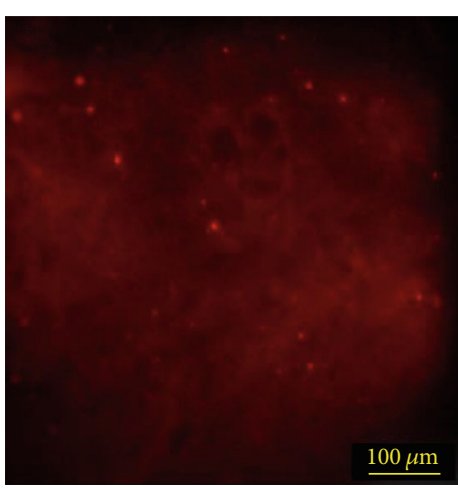

(b)

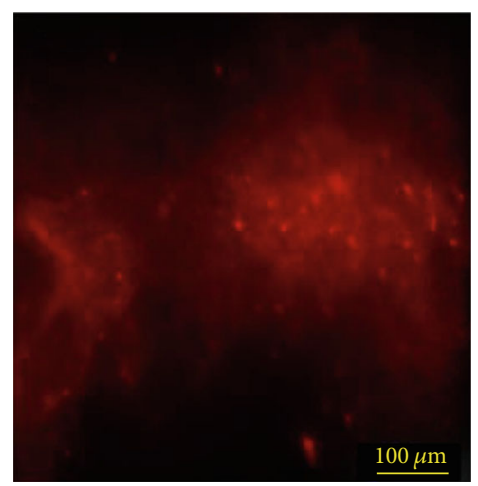

(c)

FIgURE 2: Fluorescence microscopy of archaeal cells grown on PHA accumulation medium upon $144 \mathrm{~h}$ of cultivation for strain CEJ34-14 (a), $168 \mathrm{~h}$ for strain CEJ5-14 (b), and $120 \mathrm{~h}$ for strain CEJ48-10 (c) following staining with Nile Red.

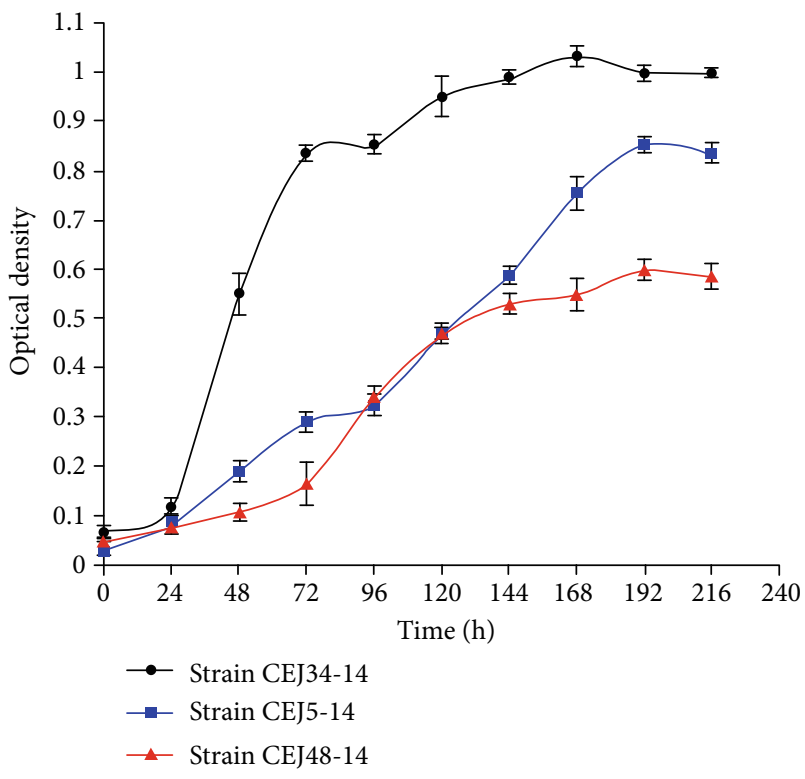

Figure 3: Growth curve over time of the strains CEJ34-14, CEJ5-14, and CEJ48-10. Optical density was taken every $24 \mathrm{~h}$ at $600 \mathrm{~nm}$. Mean values from duplicate tests are shown.

a wide range of low-cost carbon sources reduced the $\mathrm{PHB}$ production cost. Among the tested isolates, three strains CEJ34-14, CEJ5-14, and CEJ48-10 affiliated with Halorubrum chaoviator ( $99.7 \%$ of similarity), Natrinema pallidum $(99.33 \%$ of similarity), and Haloarcula tradensis (97.72\% of similarity) have been considered as the best PHB producers 9.25\%, $7.11 \%$, and $1.42 \%$ of its CDW, respectively. It was important to note that these three genera were found to be PHA accumulators in other hypersaline environments [7], but only a few species were able to utilize starch to secrete large amounts of PHB. With regard to Haloarcula investigations, no PHB was accumulated by Haloarcula species using starch except Haloarcula. sp. IRU1 which could produce 57\% PHB/CDW [17]. This species isolated from Urmia lake has been shown to produce important quantities of $\mathrm{PHB}$ (63\% of CDW) from petrochemical wastewater as a carbon source containing multiple hydrocarbons such as linear alkylbenzenes [34]. Other Haloarcula species such as Haloarcula japonica, Haloarcula amylolytica, and Haloarcula argentinensis can accumulate $\mathrm{PHB}$, and their yields obtained from glucose were $0.5,4.4$, and $6.5 \%$ (of CDW), respectively $[30,35]$. Although production of PHB has been reported from starch, glucose, and waste materials, members of Haloarcula were observed for the first time in southern Tunisian salt lakes as PHB producers [15]. Currently, there is no evidence of PHB accumulation by the Halorubrum species when starch was used as a carbon source [11]. As previously stated, two species affiliated with Halorubrum which produced PHB or PHBV (2.1-12.7\% of CDW) were able to use glucose as the sole carbon source [30]. On the other hand, the majority of members of Natrinema were found to be PHBV producers when cultivated on a medium with glucose [30] or starch [36] as the carbon sources. 


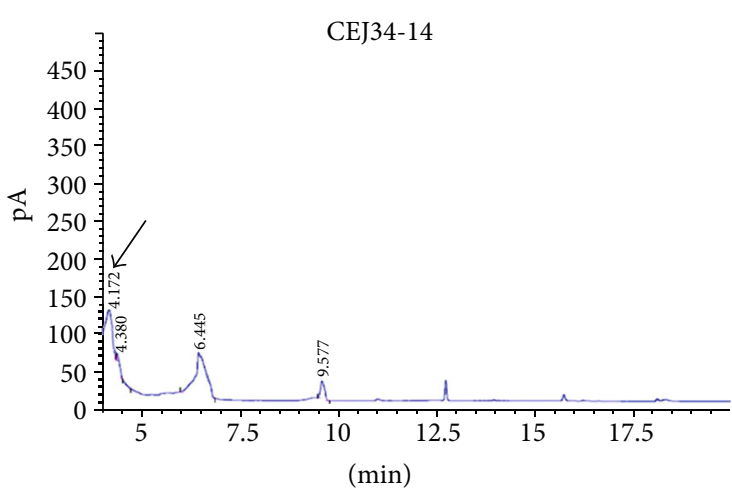

(a)

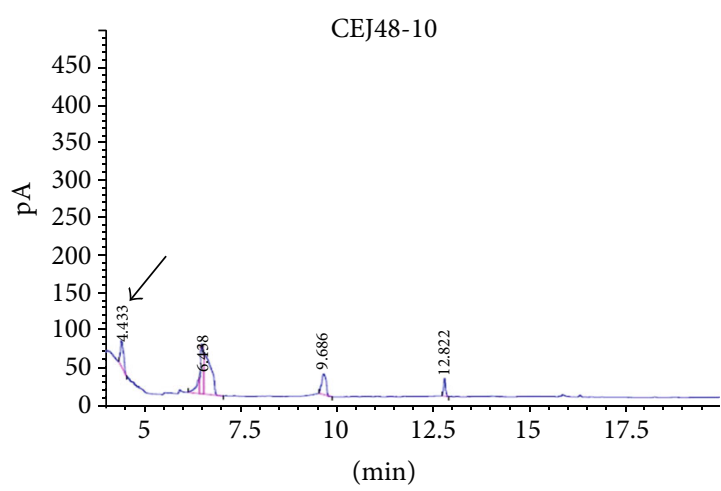

(c)

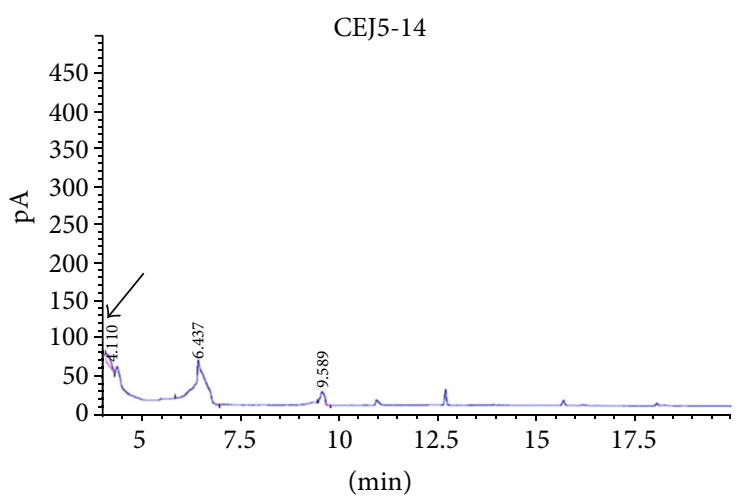

(b)

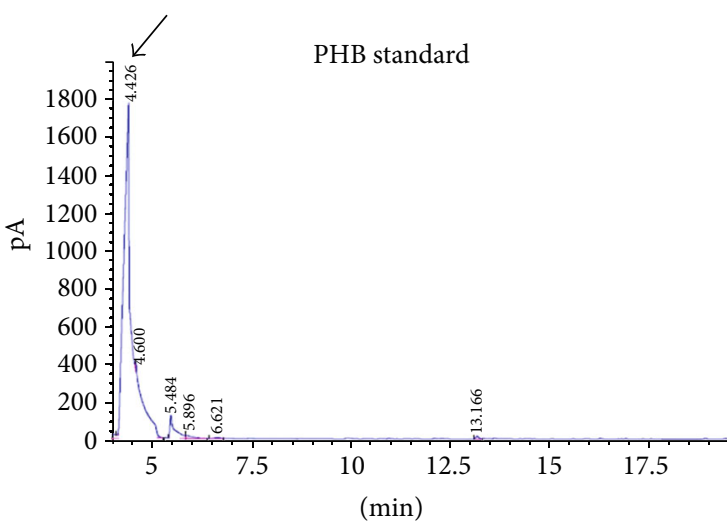

(d)

Figure 4: Chromatograms of PHA obtained from cultures of the isolates (a) CEJ34-14, (b) CEJ5-14, (c) CEJ48-10, and (d) PHB standard (Sigma). The peak at $4.4 \mathrm{~min}$ represents the 3-hydroxybutyrate methylester.

In our previous work [9], 20 extremely halophilic archaea belonging to the genera Halorubrum (17 strains), Natrinema (2 strains), and Haloterrigena (1 strain) and isolated from the sample S1-10 collected from Chott El Jerid in the dry season were screened for PHA production in the same PHAaccumulating medium used in this study. Among them, only two strains belonging to Natrinema and Haloterrigena genera have been shown to accumulate $7 \%$ of $\mathrm{PHB}$ and $3.6 \%$ of poly(3-hydroxyvalerate) (PHV), respectively, in a medium supplemented with $2 \%$ glucose. In this current study, enrichment cultures with the same sample (S1-10) and supplemented with starch showed the selection of only one PHB producer related to the genus Haloarcula. However, enrichment cultures with samples collected in the wet season and supplemented with the same carbon source revealed the presence of one species Halorubrum and a high number of Natrinema species (12 strains) with $\mathrm{PHB}$-producing ability from the samples S6W-14 and S6M-14, respectively. These findings displayed that isolation method, carbon source, season, and sampling location could influence the selection of PHB-producing archaeal species.

\section{Conclusions}

On the basis of data obtained, different archaeal isolates were obtained in pure cultures from the Tunisian desert and were able to consume starch as the sole carbon source for the PHB biosynthesis. However, the yields of PHB production in flasks batch cultures within the cells were low in comparison with other closest relatives. Therefore, future studies on fermentations optimization in batch, fed-batch, and continuous cultures using starchy and other low-cost feedstock's as well as the metabolic engineering strategies to improve both the quality and PHB productivity will be investigated.

\section{Data Availability}

The sequences have been submitted to the GenBank database under accession numbers: MN516817 to MN516830.

\section{Conflicts of Interest}

The authors declare no conflict of interest.

\section{Authors' Contributions}

Fatma Karray and Manel Ben Abdallah contributed equally to this work.

\section{Acknowledgments}

This work was supported by the Tunisian Ministry of Higher Education and Scientific Research. We thank also the reviewers for their helpful comments on this manuscript. 


\section{Supplementary Materials}

Supplementary 1. Figure S1: Cells accumulating polyhydroxyalkanoic acid staining with Sudan Black B (a) and with Nile Red (b) on agar plates. The strains Escherichia coli and Natrinema altunense strain CEJGTEA101 were used as negative and positive controls, respectively.

Supplementary 2. Figure S2: PCR amplification of PhaC (a) and PhaE (b) gene encoding for PHA synthase (class III) of positive producing strains. Lane M1 represents the molecular size marker (100 bp DNA ladder) and Lane M (1 Kb DNA ladder).

Supplementary 3. Figure S3: Phase-contrast micrographs showing cells of PHA-producing strains grown in PHAaccumulating medium at $25 \%(\mathrm{w} / \mathrm{v}) \mathrm{NaCl}$; bar, $10 \mu \mathrm{m}$.

Supplementary 4. Figure S4: (A) Restriction digestion of amplified 16S rRNA of isolates cleaving with AluI (a), MboI (b), and HaeIII (c) from the sample S1-10 and (B) from the samples S6M-14 and S6W-14. Lane M represents molecular size marker $1 \mathrm{~Kb}$ DNA ladder.

Supplementary 5. Figure S5: Growth curve over time of the isolates. Optical density was taken every $24 \mathrm{~h}$ at $600 \mathrm{~nm}$. Mean values from duplicate tests are shown.

Supplementary 6. Figure S6: Chromatograms of PHB obtained from cultures of the isolates (a) CEJ3-14, (b) CEJ6-14, (c) CEJ7-14, (d) CEJ8-14, (e) CEJ9-14, (f) CEJ1014, (g) CEJ11-14, (h) CEJ21-14, (i) CEJ24-14, (j) CEJ25-14, (k) CEJ28-14, and (l) PHB standard (Sigma).

\section{References}

[1] J. H. Song, R. J. Murphy, R. Narayan, and G. B. H. Davies, "Biodegradable and compostable alternatives to conventional plastics," Philosophical Transactions of the Royal Society B, vol. 364, no. 1526, pp. 2127-2139, 2009.

[2] R. C. Thompson, C. J. Moore, F. S. Vom Saal, and S. H. Swan, "Plastics, the environment and human health: current consensus and future trends," Philosophical Transactions of the Royal Society B: Biological Sciences, vol. 364, no. 1526, pp. 21532166, 2009.

[3] J. M. Luengo, B. García, A. Sandoval, G. Naharro, and E. R. Olivera, "Bioplastics from microorganisms," Current Opinion in Microbiology, vol. 6, no. 3, pp. 251-260, 2003.

[4] A. Steinbüchel and H. G. Schlegel, "Physiology and molecular genetics of poly( $\beta$-hydroxyalkanoic acid) synthesis in Alcaligenes eutrophus," Molecular Microbiology, vol. 5, no. 3, pp. 535-542, 1991.

[5] A. J. Anderson and E. A. Dawes, "Occurrence, metabolism, metabolic role, and industrial uses of bacterial polyhydroxyalkanoates," Microbiological Reviews, vol. 54, no. 4, pp. 450$472,1990$.

[6] R. G. Kirk and M. Ginzburg, "Ultrastructure of two species of halobacterium," Journal of Ultrastructure Research, vol. 41, no. 1-2, pp. 80-94, 1972.

[7] A. Poli, P. Di Donato, G. R. Abbamondi, and B. Nicolaus, "Synthesis, production, and biotechnological applications of exopolysaccharides and polyhydroxyalkanoates by Archaea," Archaea, vol. 2011, Article ID 693253, 13 pages, 2011.
[8] A. Legat, C. Gruber, K. Zangger, G. Wanner, and H. Stan-Lotter, "Identification of polyhydroxyalkanoates in Halococcus and other haloarchaeal species," Applied Microbiology and Biotechnology, vol. 87, no. 3, pp. 1119-1127, 2010.

[9] M. Ben Abdallah, F. Karray, and S. Sayadi, "Production of polyhydroxyalkanoates by two halophilic archaeal isolates from Chott El Jerid using inexpensive carbon sources," Biomolecules, vol. 10, no. 1, 2020.

[10] G.-Y. Tan, C.-L. Chen, L. Li et al., "Start a research on biopolymer polyhydroxyalkanoate (PHA): a review," Polymers, vol. 6, no. 3, pp. 706-754, 2014.

[11] M. Koller, "Polyhydroxyalkanoate biosynthesis at the edge of water activitiy-Haloarchaea as biopolyester factories," Bioengineering, vol. 6, no. 2, 2019.

[12] J. Han, Q. Lu, L. Zhou, J. Zhou, and H. Xiang, "Molecular characterization of the phaEC $\mathrm{Hm}_{\mathrm{Hm}}$ genes, required for biosynthesis of poly(3-hydroxybutyrate) in the extremely halophilic archaeon Haloarcula marismortui," Applied and Environmental Microbiology, vol. 73, no. 19, pp. 6058-6065, 2007.

[13] B. B. Salgaonkar, K. Mani, and J. M. Bragança, “Accumulation of polyhydroxyalkanoates by halophilic archaea isolated from traditional solar salterns of India," Extremophiles, vol. 17, no. 5, pp. 787-795, 2013.

[14] A. Pramanik, A. Mitra, M. Arumugam et al., "Utilization of vinasse for the production of polyhydroxybutyrate by Haloarcula marismortui," Folia Microbiologica, vol. 57, no. 1, pp. 7179, 2012.

[15] R. Mitra, T. Xu, H. Xiang, and J. Han, "Current developments on polyhydroxyalkanoates synthesis by using halophiles as a promising cell factory," Microbial Cell Factories, vol. 19, no. 86, pp. 1-30, 2020.

[16] J. G. Lillo and F. Rodriguez-Valera, "Effects of culture conditions on $\operatorname{poly}(\beta$-hydroxybutyric acid) production by Haloferax mediterranei," Applied and Environmental Microbiology, vol. 56, no. 8, pp. 2517-2521, 1990.

[17] M. Taran, "Synthesis of poly(3-hydroxybutyrate) from different carbon sources by Haloarcula sp. IRU1," Polymer-Plastics Technology and Engineering, vol. 50, no. 5, pp. 530-532, 2011.

[18] N. Kbir-Ariguib, D. B. H. Chehimi, and L. Zayani, "Treatment of Tunisian salt lakes using solubility phase diagrams," Pure and Applied Chemistry, vol. 73, no. 5, pp. 761-770, 2001.

[19] M. Ben Abdallah, F. Karray, N. Mhiri et al., "Characterization of Sporohalobacter salinus sp. nov., an anaerobic, halophilic, fermentative bacterium isolated from a hypersaline lake," International Journal of Systematic and Evolutionary Microbiology, vol. 65, Part 2, pp. 543-548, 2015.

[20] M. B. Abdallah, F. Karray, N. Mhiri et al., "Prokaryotic diversity in a Tunisian hypersaline lake, Chott El Jerid," Extremophiles, vol. 20, no. 2, pp. 125-138, 2016.

[21] M. B. Abdallah, F. Karray, N. Kallel et al., "Abundance and diversity of prokaryotes in ephemeral hypersaline lake Chott El Jerid using Illumina Miseq sequencing, DGGE and qPCR assays," Extremophiles, vol. 22, no. 5, pp. 811-823, 2018.

[22] F. Karray, M. B. Abdallah, N. Kallel, M. Hamza, M. Fakhfakh, and S. Sayadi, "Extracellular hydrolytic enzymes produced by halophilic bacteria and archaea isolated from hypersaline lake," Molecular Biology Reports, vol. 45, no. 5, pp. 12971309, 2018.

[23] E. F. DeLong, "Archaea in coastal marine environments," Proceedings of the National Academy of Sciences of the United States of America, vol. 89, no. 12, pp. 5685-5689, 1992. 
[24] D. J. Lane, "16S/23S rRNA sequencing," in Stackebrandt E, Nucleic acid techniques in bacterial systematics, M. Goodfellow, Ed., pp. 115-175, John Wiley \& Sons, New York, 1991.

[25] F. Karray, M. Mezghani, N. Mhiri, B. Djelassi, and S. Sayadi, "Scale-down studies of membrane bioreactor degrading anionic surfactants wastewater: isolation of new anionicsurfactant degrading bacteria," International Biodeterioration \& Biodegradation, vol. 114, pp. 14-23, 2016.

[26] M. Liu, J. E. Gonzalez, L. B. Willis, and G. C. Walker, “A novel screening method for isolating exopolysaccharide-deficient mutants," Applied and Environmental Microbiology, vol. 64, no. 11, pp. 4600-4602, 1998.

[27] P. Spiekermann, B. H. A. Rehm, R. Kalscheuer, D. Baumeister, and A. Steinbuchel, "A sensitive, viable-colony staining method using Nile red for direct screening of bacteria that accumulate polyhydroxyalkanoic acids and other lipid storage compounds," Archives of Microbiology, vol. 171, no. 2, pp. 73$80,1999$.

[28] B. B. Salgaonkar, K. Mani, and J. M. Braganca, "Characterization of polyhydroxyalkanoates accumulated by a moderately halophilic salt pan isolate Bacillus megaterium strain H16," Journal of Applied Microbiology, vol. 114, no. 5, pp. 13471356, 2013.

[29] T. M. Rose, E. R. Schultz, J. G. Henikoff, S. Pietrokovski, C. M. McCallum, and S. Henikoff, "Consensus-degenerate hybrid oligonucleotide primers for amplification of distantly related sequences," Nucleic Acids Research, vol. 26, no. 7, pp. 1628$1635,1998$.

[30] J. Han, J. Hou, H. Liu et al., "Wide distribution among halophilic archaea of a novel polyhydroxyalkanoate synthase subtype with homology to bacterial type III synthases," Applied and Environmental Microbiology, vol. 76, no. 23, pp. 78117819, 2010.

[31] H. Brandl, R. A. Gross, R. W. Lenz, and R. C. Fuller, "Pseudomonas oleovorans as a source of poly( $\beta$-hydroxyalkanoates) for potential applications as biodegradable polyesters," Applied and Environmental Microbiology, vol. 54, no. 8, pp. 19771982, 1988.

[32] V. Kumar and S. K. Tiwari, "Halocin diversity among halophilic archaea and their applications," in Microbial diversity in ecosystem sustainability and biotechnological applications, pp. 497-532, Springer, Singapore, 2019.

[33] L. Wang, Q. Liu, X. Wu et al., "Bioinformatics analysis of metabolism pathways of archaeal energy reserves," Scientific Reports, vol. 9, no. 1034, pp. 1-12, 2019.

[34] M. Taran, "Utilization of petrochemical wastewater for the production of poly(3-hydroxybutyrate) by Haloarcula sp. IRU1," Journal of Hazardous Materials, vol. 188, no. 1-3, pp. 26-28, 2011.

[35] B. Nicolaus, L. Lama, E. Esposito et al., "Haloarcula spp able to biosynthesize exo- and endopolymers," Journal of Industrial Microbiology and Biotechnology, vol. 23, no. 6, pp. 489-496, 1999.
[36] O. Danis, A. Ogan, P. Tatlican et al., "Preparation of poly(3hydroxybutyrate-co-hydroxyvalerate) films from halophilic archaea and their potential use in drug delivery," Extremophiles, vol. 19, no. 2, pp. 515-524, 2015.

[37] R. Mahansaria, A. Dhara, A. Saha, S. Haldar, and J. Mukherjee, "Production enhancement and characterization of the polyhydroxyalkanoate produced by Natrinema ajinwuensis (as synonym) $\equiv$ Natrinema altunense strain RM-G10," International Journal of Biological Macromolecules, vol. 107, no. Part B, pp. 1480-1490, 2018. 